\title{
BMJ Open Differences in progression by surgical specialty: a national cohort study
}

\author{
Carla Hope (D) , ${ }^{1}$ Jonathan Lund, ${ }^{2}$ Gareth Griffiths, ${ }^{3}$ David Humes ${ }^{4}$
}

To cite: Hope C, Lund J, Griffiths $\mathrm{G}$, et al. Differences in progression by surgical specialty: a national cohort study. BMJ Open 2022;12:e053391. doi:10.1136/ bmjopen-2021-053391

- Prepublication history for this paper is available online. To view these files, please visit the journal online (http://dx.doi. org/10.1136/bmjopen-2021053391).

Received 12 May 2021 Accepted 19 November 2021

Check for updates

(C) Author(s) (or their employer(s)) 2022. Re-use permitted under CC BY-NC. No commercial re-use. See rights and permissions. Published by BMJ.

${ }^{1}$ Division of Graduate Entry Medicine and Health Sciences, University of Nottingham, Nottingham, UK

${ }^{2}$ Division of Medical Sciences and Graduate Entry Medicine,

University of Nottingham, Derby, UK

${ }^{3}$ Department of Vascular Surgery, Ninewells Hospital and Medical School, Dundee, UK ${ }^{4}$ NIHR Nottingham Biomedical Research Centre (BRC), Nottingham University, Nottingham, UK

Correspondence to Carla Hope; carlahope@nhs.net

\section{ABSTRACT}

The aim of surgical training across the 10 surgical specialties is to produce competent day 1 consultants. Progression through training in the UK is assessed by the Annual Review of Competency Progression (ARCP).

Objective This study aimed to examine variation in ARCP outcomes within surgical training and identify differences in outcomes between specialties.

Design A national cohort study using data from the UK Medical Education Database was performed. ARCP outcome was the primary outcome measure. Multilevel ordinal regression analyses were performed, with ARCP outcomes nested within trainees.

Participants Higher surgical trainees (ST3-ST8) from nine UK surgical specialties were included (vascular surgery was excluded due to insufficient data). All surgical trainees across the UK with an ARCP outcome between 2010 and 2017 were included.

Results Eight thousand two hundred and twenty trainees with an ARCP outcome awarded between 2010 and 2017 were included, comprising 31788 ARCP outcomes. There was substantial variation in the proportion of nonstandard outcomes recorded across specialties with general surgery trainees having the highest proportion of non-standard outcomes (22.5\%) and urology trainees the fewest (12.4\%). After adjustment, general surgery trainees were 1.3 times more likely to receive a nonstandard ARCP outcome compared with trainees in trauma and orthopaedics (T\&O) (OR 1.33, 95\% Cl 1.21 to 1.45 , $p=0.001$ ). Urology trainees were $36 \%$ less likely to receive a non-standard outcome compared with T\&O trainees (OR $0.64,95 \% \mathrm{Cl} 0.54$ to $0.75, \mathrm{p}<0.001)$. Female trainees and older age were associated with non-standard outcomes (OR $1.11,95 \% \mathrm{Cl} 1.02$ to $1.22, \mathrm{p}=0.020 ;$ OR $1.04,95 \% \mathrm{Cl}$ 1.03 to $1.05, p<0.001)$.

Conclusion There is wide variation in the training outcome assessments across surgical specialties. General surgery has higher rates of non-standard outcomes compared with other surgical specialties. Across all specialties, female sex and older age were associated with non-standard outcomes.

\section{INTRODUCTION}

Surgical training in the UK is comprised of 10 specialties: cardiothoracics, ENT (Ear, Nose and Throat surgery), general surgery, neurosurgery, oral and maxillofacial surgery (OMFS), paediatric surgery, plastic surgery, trauma and orthopaedics, urology and vascular. Successful entrants to surgical
Strengths and limitations of this study

- This is the first study investigating factors affecting the Annual Review of Competency Progression outcome across all surgical specialties.

- The major strength of the study is the large sample size comprising all higher surgical trainees between 2010 and 2017.

- Unlike previous studies, this study uses data from reliable sources and is not dependent on survey data.

- Limitations include the inability to investigate the causes behind our findings due to the nature of the analysis.

specialty training in the UK are enrolled into a 6-year programme within their specialty of interest, termed Higher Surgical Training. This follows a minimum of 4years' clinical experience after medical school graduation. Specialty training is mapped to a national curriculum which defines the levels of specialty-specific knowledge and skills required for completion of training around academic, procedural and clinical competence. ${ }^{1}$ Progression to the next stage of training is dependent on meeting curriculum targets and is assessed by the Annual Review of Competency Progression (ARCP). ${ }^{2}$ ARCP is the formal and structured evaluation of a portfolio of evidence to ensure a doctor has achieved the required competencies to enable satisfactory progression through each stage of medical training. ${ }^{2}$ The endpoint of successful completion of surgical training is the award of Certificate of Completion of Training (CCT) which allows entry onto the General Medical Council (GMC) specialist register. $^{3}$

The aim of surgical training is the same across all specialties: to enable surgeons to acquire the curriculum standards and the professional responsibilities to practise as a day 1 consultant surgeon. ${ }^{4}$ If the training programme is meeting the needs of trainees, we would expect similar proportions of ARCP outcomes across all surgical specialties. The GMC is committed to promoting excellence 
in the delivery of postgraduate medical education and therefore it is important to ensure consistency of training standards and assessment across surgical training. ${ }^{5}$

Differential attainment refers to the differences in performance between different demographic groups ${ }^{6}$ and within surgical training this is reported internationally. ${ }^{7-9}$ Other studies have demonstrated differences in surgical training outcomes by gender, age and place of medical qualification ${ }^{10}{ }^{11}$; however, to date, there have been no studies comparing ARCP outcomes across surgical specialties.

\section{Aim}

To examine variation in ARCP outcomes within UK surgical specialty training and identify any differences between specialties.

\section{METHOD}

We performed a cohort study using anonymised data from the UK Medical Education Database (UKMED), approval number $3506 .{ }^{12}$ UKMED collates data on sociodemographic and educational information for UK and international medical students and follows these students through their medical training, adding data as they progress. The database includes all UK medical students commencing studies in 2002 onwards, and from 2012 onwards, those graduating from non-UK medical schools and entering UK postgraduate training are included. For each graduate, ARCP outcomes are linked to demographic information. These data can be modelled to assess the differences in ARCP outcomes between surgical specialties. These data have been used to study outcomes and progression in medical specialties and foundation programme extensively and have been shown to be reliable. $^{13-15}$

\section{Patient and public involvement}

Patient and public involvement was not sought given the educational nature of the study and the fact no patients were included in the study.

\section{Outcome measure}

The outcome measure in this study was ARCP outcome. ARCP outcome was converted into an ordinal category following which has previously been validated. ${ }^{16}$

- Group 1: 'satisfactory progress/training completed': ARCP outcomes 1 and 6 (see table 1).

- Group 2: 'insufficient evidence presented': ARCP outcome 5.

- Group 3: 'targeted training required (no extended time)': ARCP outcome 2.

- Group 4: 'extended training time required/left programme': ARCP outcome 3 or 4.

Any non-training outcomes were not included in this analysis, for example, those out of programme for research or experience.

\begin{tabular}{ll}
\hline Table 1 & ARCP outcomes \\
\hline Outcome & Description \\
\hline 1 & $\begin{array}{l}\text { Satisfactory progress - achieving progress } \\
\text { and the development of competences at the } \\
\text { expected rate }\end{array}$ \\
\hline 2 & $\begin{array}{l}\text { Development of specific competences } \\
\text { required-additional training time not required }\end{array}$ \\
\hline 3 & $\begin{array}{l}\text { Inadequate progress - additional training time } \\
\text { required }\end{array}$ \\
\hline 5 & $\begin{array}{l}\text { Released from training programme-with or } \\
\text { without specified competences }\end{array}$ \\
\hline 6 & $\begin{array}{l}\text { Incomplete evidence presented-additional } \\
\text { training time may be required }\end{array}$ \\
& $\begin{array}{l}\text { Gained all required competences - will be } \\
\text { recommended as having completed the training } \\
\text { programme (core of specialty) and if in a run- } \\
\text { through training programme or higher training } \\
\text { programme, will be recommended for award of } \\
\text { a CCT or Certificate of Eligibility for Specialist } \\
\text { Registration/Certificate of Eligibiltiy for General } \\
\text { Practice Registration } \\
\text { Fixed-term posts (split into 1-4 as above) } \\
\text { Out of programme (OOP) for clinical experience, } \\
\text { research or a career break (OOPE/OOPR/OOPC) }\end{array}$ \\
\hline 8 &
\end{tabular}

Standard outcomes are ARCP outcomes 1, 6 and 7.1. Nonstandard outcomes are ARCP outcomes 2, 7.2, 3 and 4. Outcome 5 is awarded when insufficient evidence is presented with a window of 2 weeks for the trainee to provide missing evidence before a standard or non-standard outcome is awarded, Outcome 8 is awarded when out of programme and neither this nor any outcome 7 were included in the analysis.

ARCP, Annual Review of Competency Progression; CCT, Certificate of Completion of Training.

\section{Cohort derivation}

All surgical trainees (ST3-ST8) from cardiothoracics, ENT, general surgery, neurosurgery, OMFS, paediatric surgery, plastic surgery, trauma and orthopaedics, and urology with an ARCP outcome recorded between 2010 and 2017 were included. Trauma and orthopaedic surgery was taken as the reference category in the regression analyses as this had the largest number of outcomes. In the event of more than one ARCP outcome within 12 months, the first chronological outcome was used. It was not possible to include vascular surgery as this only became a separate specialty in 2013 and the number of outcomes was too small $(\mathrm{N}=189)$.

\section{Predictor variable selection}

Age, sex, region of primary medical qualification, less than full-time training and year of ARCP were selected as confounding factors due to the variation in these demographics across specialties. Region of primary medical qualification was categorised into UK, European Economic Area and International Medical Graduates. ${ }^{17}$ Less than full-time training requires the same standard of 
competencies to be met at ARCP; however, the training time may be longer.

\section{Statistical analysis}

Descriptive statistics were derived to describe the satisfactory and non-standard cohorts. Demographic data were rounded to ensure anonymity as per guidance from the Higher Education Statistics Agency. ${ }^{18}$ Missing data were coded as a separate category within each variable. $X^{2}$ test was used to compare the difference in the proportion of satisfactory outcomes compared with general surgery, as general surgery had the highest proportion of nonstandard outcomes. Predicted probabilities of obtaining each ARCP outcome were calculated for each specialty to allow comparison across all specialties and displayed in a caterpillar plot using Stata post-estimation commands. A multilevel ordinal regression was performed, with a random intercept at the trainee level. This takes into account the fact that trainees had multiple ARCPs over time. Wald's test and likelihood ratio tests were used to obtain $\mathrm{p}$ values.

A multilevel multiple ordinal regression was performed to investigate the odds of non-standard ARCP outcome by specialty. ORs with $95 \%$ CIs adjusted for sex, age, region of primary medical qualification, less than full-time training and year of ARCP were reported. P values of $<0.05$ were taken as significant. Analyses were performed using Stata V.15 (StataCorp, College Station, Texas, USA). ${ }^{19}$

\section{RESULTS}

The analysis included 8220 trainees across all specialties, comprising 31788 ARCP outcomes. Seventy-six per cent of all trainees were male. The proportion of female trainees varied from $15 \%$ in trauma and orthopaedics to $49 \%$ in paediatric surgery (table 2). The median age at ARCP was 35 years (IQR 32-37). The majority of trainees $(81 \%)$ had attended a UK medical school. Eighty-two per cent (25 991 of 31788 ) of the outcomes were satisfactory; $8 \%$ provided insufficient evidence, $6 \%$ required targeted training and $4 \%$ either required extended training time or were asked to leave the programme (table 3). Between 2010 and 2017, of the non-standard outcomes, 1.3\% (75 of 5797) were outcome 4 (released from training programme). Between 2010 and 2017, standard outcomes reduced from $85 \%$ to $78 \%(\mathrm{p}<0.001)$.

Trauma and orthopaedics had the largest proportion of ARCP outcomes, followed by general surgery (table 3). There was wide variation in the proportion of nonstandard outcomes between specialties (table 3). General surgery had the lowest proportion of standard outcomes $(77.5 \%)$, compared with $87.6 \%$ in urology. Maxillofacial surgery had the greatest proportion $(6.9 \%)$ of extended training/left programme outcomes while ENT had the lowest at $2.2 \%$. All specialties except paediatric surgery had a significantly greater number of satisfactory outcomes than general surgery on $\mathrm{X}^{2}$ test (table 3 ). Figure 1 illustrates the variation in ARCP outcome by

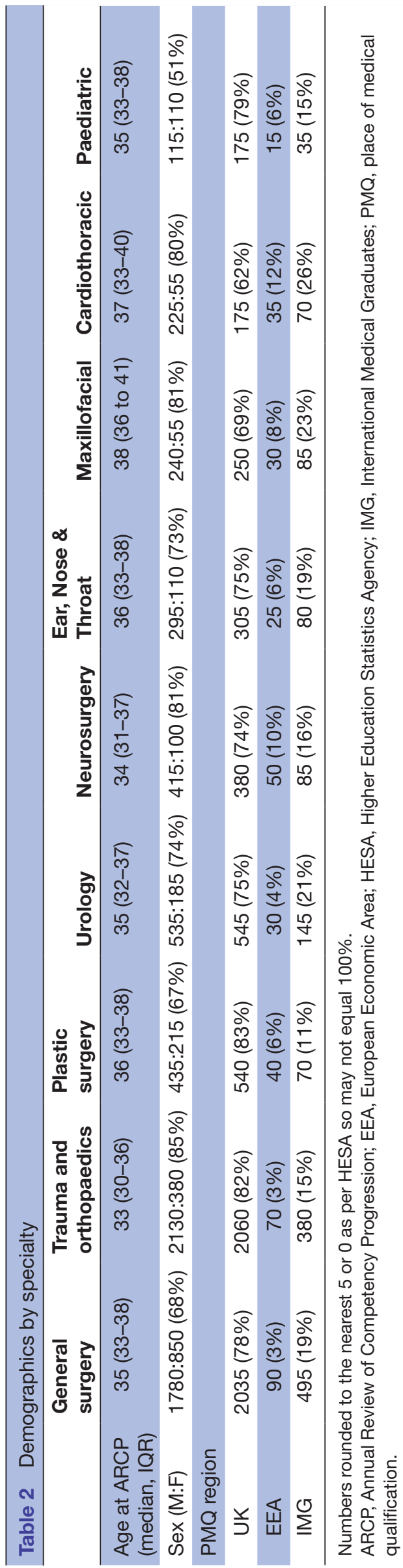


Table 3 Number of ARCPs by specialty

\begin{tabular}{|c|c|c|c|c|c|}
\hline Specialty & $\begin{array}{l}\text { Satisfactory } \\
\text { N (\%) }\end{array}$ & $\begin{array}{l}\text { Insufficient } \\
\text { evidence } \\
\mathrm{N}(\%)\end{array}$ & $\begin{array}{l}\text { Targeted training } \\
\mathbf{N}(\%)\end{array}$ & $\begin{array}{l}\text { Extended training/ } \\
\text { left programme } \\
\mathrm{N}(\%)\end{array}$ & $\begin{array}{l}\text { Total no of ARCPs } \\
\text { N (\%) }\end{array}$ \\
\hline General surgery & 7859 (77.5) & 1005 (9.9) & $710(7.0)$ & $562(5.5)$ & $10136(32)$ \\
\hline $\begin{array}{l}\text { Trauma and } \\
\text { orthopaedics }\end{array}$ & $9098(82.6)^{*}$ & 917 (8.3) & $638(5.8)$ & 358 (3.3) & $11011(35)$ \\
\hline Plastic surgery & $2091(85.5)^{\star}$ & $181(7.4)$ & $89(3.6)$ & $84(3.4)$ & $2445(8)$ \\
\hline Urology & $2091(87.6)^{\star}$ & $149(6.2)$ & $86(3.6)$ & $62(2.6)$ & $2388(7)$ \\
\hline Neurosurgery & $1555(84.5)^{\star}$ & $121(6.6)$ & $81(4.4)$ & $83(4.5)$ & $1840(6)$ \\
\hline Ear, Nose \& Throat & $1127(86.5)^{\star}$ & $81(6.2)$ & $66(5.1)$ & $29(2.2)$ & $1303(4)$ \\
\hline Maxillofacial & $812(81.0)^{\star}$ & $74(7.4)$ & $47(4.7)$ & $69(6.9)$ & $1002(3)$ \\
\hline Cardiothoracic & $782(83.1)^{\star}$ & $73(7.8)$ & $37(3.9)$ & $49(5.2)$ & $941(3)$ \\
\hline Paediatric & 576 (79.8) & $60(8.3)$ & $45(6.2)$ & $41(5.7)$ & $722(2)$ \\
\hline Total & 25991 (81.8) & 2661 (8.4) & 1799 (5.6) & $1337(4.2)$ & $31788(100)$ \\
\hline
\end{tabular}

${ }^{*}$ All specialties had a significantly $(p<0.001)$ different number of satisfactory outcomes compared with general surgery using $x^{2}$, except paediatric surgery $(p=0.162)$.

ARCP, Annual Review of Competency Progression.

specialty. General surgery had the lowest predicted probability of a satisfactory outcome comparing across all specialties and urology had the greatest. General surgery and paediatric surgery had the greatest predicted probability of all other non-standard outcomes. The results from the univariable and multiple ordinal regression analysis can be found in table 4 .

\section{DISCUSSION}

This is the first study investigating the differences in ARCP outcome between surgical specialties. When combining all surgical specialties, women and older trainees are less likely to receive a standard ARCP outcome. The

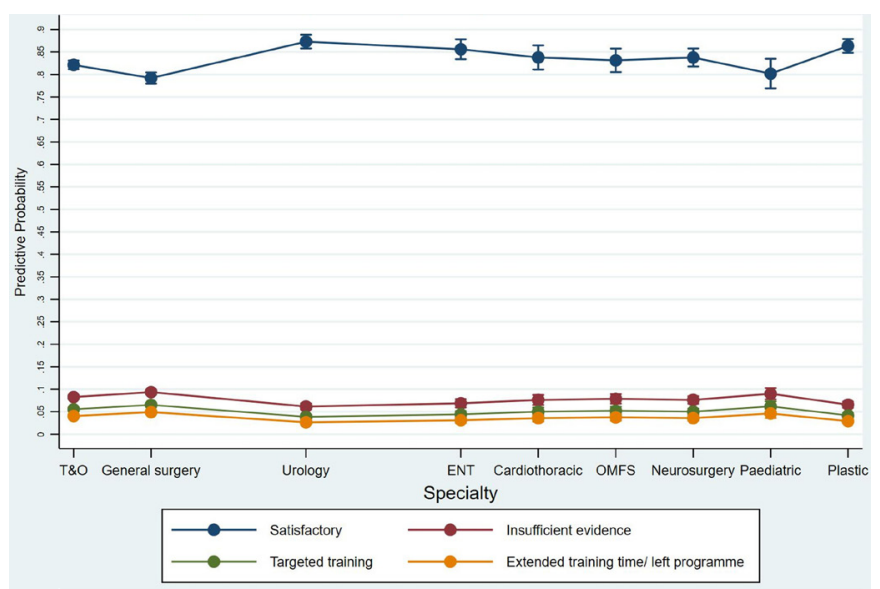

Figure 1 Predicted probabilities of ARCP outcome by surgical specialty. General surgery has the lowest predictive probability of a satisfactory ARCP outcome across all specialties, while urology has the greatest. ARCP, Annual Review of Competency Progression; ENT, Ear, Nose \& Throat surgery; OMFS, oral and maxillofacial surgery; T\&O, trauma and orthopaedics. likelihood of a non-standard outcome has increased throughout time. There is between-specialty variation in ARCP outcomes with general surgery trainees significantly more likely to have a non-standard ARCP outcome compared with other specialties. Across the specialties, $1.3 \%$ of trainees are released from training (outcome 4).

Surgery remains dominated by men and attitudes towards women in surgery have been challenged in recent years. One study reported that $59 \%$ of women in surgery had experienced workplace discrimination, there was also a perception that the surgical environment is better equipped to support male trainees. ${ }^{20}$ Other studies have found that female trainees have adverse outcomes in surgical training. In a meta-analysis comprising 17407 surgical trainees across the world, women were found to have a higher pooled attrition than men. ${ }^{21}$ A 2019 study found that female general surgery residents in the USA were significantly less likely to be granted operative autonomy by faculty than men, ${ }^{7}$ similar findings were seen among New Zealand general surgery trainees. ${ }^{22}$ The finding that women across all specialties have adverse outcomes requires investigation at the specialty level.

Between 2010 and 2017, the likelihood of non-standard ARCP outcome has increased. The possible explanations for this include increasing experience of the ARCP panel in ensuring criteria are met, changes in training quality and difficulties meeting ARCP requirements. Other factors such as increased familiarity of the system and requirements since its introduction in 2007, more rigorous application of the criteria and the recognition that it is more beneficial to trainees to issue a non-standard outcome earlier than later may also play a role in this finding. The largest increase in non-standard outcomes was in the insufficient evidence group. This may be due to increased service provision demands leaving less time for portfolio 
Table 4 Multilevel ordinal regression showing factors associated with non-standard ARCP outcome

\begin{tabular}{|c|c|c|c|c|}
\hline & Unadjusted OR $(95 \% \mathrm{Cl})$ & $P$ value & Adjusted OR (95\% Cl) & $P$ value \\
\hline \multicolumn{5}{|l|}{ Specialty } \\
\hline Trauma and orthopaedics & 1 & - & 1 & - \\
\hline Plastic surgery & $0.81(0.70$ to 0.95$)$ & 0.010 & 0.70 (0.60 to 0.82$)$ & $<0.001$ \\
\hline Urology & 0.66 (0.56 to 0.78$)$ & $<0.001$ & 0.64 (0.54 to 0.75$)$ & $<0.001$ \\
\hline Ear, Nose \& Throat & 0.75 (0.61 to 0.92$)$ & 0.005 & 0.76 (0.61 to 0.93$)$ & 0.009 \\
\hline Maxillofacial & 1.18 (0.95 to 1.47$)$ & 0.125 & $0.93(0.75$ to 1.16$)$ & 0.506 \\
\hline Cardiothoracic surgery & 0.96 (0.77 to 1.21$)$ & 0.753 & 0.88 (0.70 to 1.10$)$ & 0.268 \\
\hline Paediatric surgery & 1.28 (1.00 to 1.63$)$ & 0.048 & 1.16 (0.91 to 1.48$)$ & 0.228 \\
\hline Female & 1.22 (1.12 to 1.33$)$ & $<0.001$ & 1.11 (1.02 to 1.22$)$ & 0.020 \\
\hline UK & 1 & - & 1 & - \\
\hline EEA & $0.93(0.77$ to 1.13$)$ & 0.482 & 0.89 (0.73 to 1.08$)$ & 0.253 \\
\hline IMG & 0.77 (0.69 to 0.87 ) & $<0.001$ & $0.69(0.61$ to 0.78$)$ & $<0.001$ \\
\hline \multicolumn{5}{|l|}{ Less than full-time training } \\
\hline Yes & 1.21 (1.07 to 1.36$)$ & 0.002 & 1.11 (0.98 to 1.26$)$ & 0.093 \\
\hline Missing & $0.50(0.41$ to 0.62$)$ & $<0.001$ & 0.51 (0.41 to 0.63 ) & $<0.001$ \\
\hline Year of ARCP & 1.07 (1.05 to 1.08$)$ & $<0.001$ & 1.04 (1.03 to 1.06$)$ & $<0.001$ \\
\hline
\end{tabular}

ARCP, Annual Review of Competency Progression; EEA, European Economic Area; IMG, International Medical Graduates; PMQ, place of medical qualification.

admin and changing curriculum requirements. Previous studies have described a decrease in operative case load for surgical trainees over time. ${ }^{23-25}$ A large proportion of UK trainees struggle to meet operative case requirements, with $85 \%$ reporting coming in on off days to gain extra experience. ${ }^{26}$ The variation in ARCP outcomes over time is likely multifactorial and beyond the scope of this study.

There are a number of factors which may contribute to the difference in ARCP outcomes between surgical specialties. Until the introduction of the new surgical curriculum in August 2021, there were differences in requirements for CCT between specialties. These inconsistencies have been highlighted in a 2019 paper by Wood et $a l .{ }^{27}$ For example, the academic requirement for CCT in general surgery requires three peer-reviewed publications by the end of training, urology trainees require two, while paediatric surgery requires four, cardiothoracic trainees are required to deliver six presentations while those in ENT have no specified number. These different thresholds of attainment may therefore contribute to variation seen in the outcomes awarded in this study. Regardless of surgical specialty, there are universal requirements of a day 1 consultant. In the 2021 Joint Committee on Surgical Training curriculum update, the academic requirements are now uniform across all surgical specialties; however, variation in operative case load and work based assessments persists. ${ }^{28} 29$
The academic and management and leadership responsibilities are likely to be the same across specialties and therefore we support this standardisation. The aim of the surgical training programmes is to produce competent day 1 consultants, this study should prompt a review of these requirements across specialties.

The top performing specialties (urology, plastic surgery and ENT) have a smaller number of trainees which may increase the number of training opportunities and the ease of completing work-based assessments. In smaller specialties, it is likely that trainees and trainers will have greater training continuity, this has been shown to increase intraoperative entrustment. ${ }^{30} 31$ Examples of good practice from well-performing specialties should be highlighted and shared in order to improve the quality of surgical training for all.

In the USA, general surgery residents have a higher rate of attrition compared with other specialties. ${ }^{32-34}$ However, the failure to complete residency in these studies is largely due to voluntary attrition as opposed to unsatisfactory progression. Similarly, in a Canadian study across surgical specialties, general surgery residents were the most likely to consider leaving the programme. ${ }^{35}$ The main reason for this was concerns regarding work-life balance. Reassuringly, we have found that a low proportion of trainees are asked to leave the programme. However, the increasing rates of non-standard ARCP outcomes found in our study 
may negatively impact on trainee satisfaction and have a knock-on effect on attrition rates in the future.

Surgical trainees have been found to have low rates of career satisfaction and higher rates of burnout compared with trainees in other medical specialties. ${ }^{36}$ In a 2019 meta-analysis, general surgery trainees had the highest rate of burnout among the surgical subspecialties with a $58 \%$ prevalence rate of burnout. ${ }^{37}$ Burnout was defined as a long-term stress reaction marked by emotional exhaustion, depersonalisation and reduced personal accomplishment. ${ }^{38}$ Orthopaedics and neurosurgery had a slightly lower rate at $55 \%$ and $52 \%$, respectively. ${ }^{37}$

The major strength of this study is that it captures a large contemporary cohort of surgical trainees across specialties. UKMED contains data from reliable sources and avoids the reliance on survey data as studies in this field often do. The grouping of ARCP outcomes into an ordinal scale has been previously used for studies based on data from UKMED. ${ }^{10111639}$ Due to the small numbers of outcome 4 (released from training programme) awarded nationally, a subgroup analysis on this cohort is not possible due to anonymity issues. Therefore, outcome 4 is combined with outcome 3 (additional training time) in our analysis. There may be different factors contributing to the award of these outcomes that will not be accounted for by combining them. One limitation is the inability to include vascular surgery within the analysis, due to the small number of ARCP outcomes available. Ethnicity data were not available for a large proportion of the study cohort and therefore it was not possible to include ethnicity as a variable; this is an area that needs to be addressed in further research. It is not possible to determine the underlying causes for the findings in this study, which are likely to be multifactorial. Further detailed work examining individual ARCP outcomes is required and a repeat review of variation between specialties once the new curriculum is well established.

\section{CONCLUSION}

There is a wide variation in the use of non-standard ARCP outcomes across UK surgical specialties with female sex and older age at ARCP being associated with non-standard outcomes. Furthermore, the use of non-standard outcomes is becoming more frequent over time. Possible explanations for this include variation in CCT requirements, training quality or difficulty meeting ARCP standards. The finding that some specialties and groups of trainees have lower rates of standard ARCP outcomes requires further investigation to ensure consistent training quality and assessment regardless of specialty. An in-depth study including details of workbased assessments, logbook data and supervisor reports per specialty could help to further understand the variation in outcomes.

Twitter Carla Hope @carlahope1988
Acknowledgements I am a postgraduate of an affiliated association which is funding the publishing charge.

Contributors All authors were responsible for editing and drafting the final manuscript. $\mathrm{CH}$ performed the statistical analysis with input from $\mathrm{DH}$. $\mathrm{DH}$ and $\mathrm{CH}$ were the guarantors of the work.

Funding The authors have not declared a specific grant for this research from any funding agency in the public, commercial or not-for-profit sectors.

Competing interests None declared.

Patient and public involvement Patients and/or the public were not involved in the design, or conduct, or reporting, or dissemination plans of this research.

Patient consent for publication Not required.

Ethics approval This study does not involve human participants.

Provenance and peer review Not commissioned; externally peer reviewed.

Data availability statement Data are available upon reasonable request. Data may be obtained from a third party and are not publicly available. The data used in this study were made available upon application to UKMED and accessed via virtual desktop. Requests for data should be made directly to UKMED.

Open access This is an open access article distributed in accordance with the Creative Commons Attribution Non Commercial (CC BY-NC 4.0) license, which permits others to distribute, remix, adapt, build upon this work non-commercially, and license their derivative works on different terms, provided the original work is properly cited, appropriate credit is given, any changes made indicated, and the use is non-commercial. See: http://creativecommons.org/licenses/by-nc/4.0/.

ORCID iD

Carla Hope http://orcid.org/0000-0002-2834-7933

\section{REFERENCES}

1 Joint Committee on Surgical Training. The joint Committee on surgical training; about us 2018, 2020. Available: https://www.jcst. org/about-us/ [Accessed 09 Mar 2020].

2 Health Education England. The gold guide, 2018. Available: https:// specialtytraining.hee.nhs.uk/

3 Joint Committee on Surgical Training. Certification, 2018. Available: https://www.jcst.org/uk-trainees/str-trainees/certification/ [Accessed 09 Mar 2020].

4 General Medical Council. The Intercollegiate surgical curriculum: educating the surgeons of the future, 2018. Available: https://www. gmc-uk.org/-/media/documents/General_Surgery_inc._Trauma TIG_approved_Jul_17_.pdf_72509288.pdf [Accessed 27 Dec 2020].

5 General Medical Council. Promoting excellence, 2020. Available: https://www.gmc-uk.org/education/standards-guidance-andcurricula/standards-and-outcomes/promoting-excellence [Accessed 07 Jan 2021].

6 Regan de Bere S, Nunn S, Nasser M. Understanding differential attainment across medical training pathways: a rapid review of the literature, 2015

7 Meyerson SL, Odell DD, Zwischenberger JB, et al. The effect of gender on operative autonomy in general surgery residents. Surgery 2019;166:738-43.

8 Burgos CM, Josephson A. Gender differences in the learning and teaching of surgery: a literature review. Int $J$ Med Educ 2014;5:110-24

9 Scrimgeour D, Cleland J, Lee AJ, et al. Predictors of success in the Intercollegiate membership of the Royal College of surgeons (MRCS) examination. Ann R Coll Surg Engl 2018;100:424-7.

10 Hope C, Boyd-Carson H, Phillips H, et al. Personal characteristics associated with progression in general surgery training: a longitudinal cohort study. The Bulletin of the Royal College of Surgeons of England 2021;103:046-53.

11 Hope C, Humes D, Griffiths G, et al. Personal characteristics associated with progression in trauma and orthopaedic specialty training: a longitudinal cohort study. J Surg Educ 2022;79:253-9.

12 Dowell J, Cleland J, Fitzpatrick S, et al. The UK medical education database (UKMED) what is it? why and how might you use it? BMC Med Educ 2018;18:6.

13 Woolf $\mathrm{K}$, Jayaweera $\mathrm{H}$, Unwin $\mathrm{E}$, et al. Effect of sex on specialty training application outcomes: a longitudinal administrative data study of UK medical graduates. BMJ Open 2019;9:e025004.

14 Kumwenda B, Cleland JA, Prescott GJ, et al. Geographical mobility of UK trainee doctors, from family home to first job: a national cohort study. BMC Med Educ 2018;18:314. 
15 Cleland J, Prescott G, Walker K, et al. Are there differences between those doctors who apply for a training post in Foundation year 2 and those who take time out of the training pathway? A UK multicohort study. BMJ Open 2019;9:e032021.

16 Tiffin PA, Illing J, Kasim AS, et al. Annual review of competence progression (ARCP) performance of doctors who passed professional and linguistic assessments board (PLAB) tests compared with UK medical graduates: national data linkage study. BMJ 2014;348:g2622.

17 Seicean A, Alan N, Seicean S, et al. Surgeon specialty and outcomes after elective spine surgery. Spine 2014;39:1605-13.

18 Higher Education Statistics Agency. Rounding and suppression to anonymise statistics, 2018. Available: https://www.hesa.ac.uk/about/ regulation/data-protection/rounding-and-suppression-anonymisestatistics [Accessed 12 Sep 2019].

19 StataCorp LLC. Stata Statistical Software: Release 15 [program]. College Station TX, 2017.

20 Bellini MI, Graham Y, Hayes C, et al. A woman's place is in theatre: women's perceptions and experiences of working in surgery from the association of Surgeons of great britain and ireland women in surgery Working group. BMJ Open 2019;9:e024349.

21 Hope C, Reilly J-J, Griffiths G, et al. Factors associated with attrition and performance throughout surgical training: a systematic review and meta-analysis. World J Surg 2021;45:429-42.

22 Joh DB, van der Werf B, Watson BJ, et al. Assessment of autonomy in operative procedures among female and male New Zealand general surgery trainees. JAMA Surg 2020;155:1019-26.

23 Morris-Stiff G, Ball E, Torkington J, et al. Registrar operating experience over a 15-year period: more, less or more or less the same? Surgeon 2004;2:161-4.

24 Sher JL, Reed MR, Calvert P, et al. Influencing the national training agenda. The UK \& Ireland orthopaedic eLogbook. J Bone Joint Surg Br 2005;87:1182-6.

25 Oakley JE, Clewer GJ, Cool WP, et al. The effect of the EWTD on orthopaedic specialist training. Bull R Coll Surg Engl 2005;87:320-1.

26 Marriott JC, Purdie H, Millen A, et al. The lost opportunities for surgical training in the NHS. Bulletin 2011;93:202-6.
27 Wood S, James OP, Hopkins L, et al. Variations in competencies needed to complete surgical training. BJS Open 2019;3:852-6.

28 Luton O, James OP, Mellor K, et al. Surgical curriculum concordance: requiem for the educational DREAM. Postgrad Med J 2021:postgradmedj-2020-139385.

29 Joint Committee on surgical Training. The new surgical curriculum for August 2021. Available: https://www.iscp.ac.uk/iscp/curriculum2021/ [Accessed 06 Jul 2021].

30 Sandhu G, Thompson J, Matusko N, et al. Greater faculty familiarity with residents improves intraoperative entrustment. Am J Surg 2020;219:608-12.

31 Sandhu G, Magas CP, Robinson AB, et al. Progressive entrustment to achieve resident autonomy in the operating room: a national qualitative study with general surgery faculty and residents. Ann Surg 2017;265:1134-40.

32 Bauer JM, Holt GE. National orthopedic residency attrition: who is at risk? J Surg Educ 2016;73:852-7.

33 Meyerson J, Yang M, Pearson G. Attrition in plastic surgery residencies. Plast Reconstr Surg Glob Open 2016;4:e1102.

34 Prager JD, Myer CM, Myer CM. Attrition in otolaryngology residency. Otolaryngol Head Neck Surg 2011;145:753-4.

35 Adams S, Ginther DN, Neuls E, et al. Attitudes and factors contributing to attrition in Canadian surgical specialty residency programs. Can J Surg 2017;60:247-52.

36 Alobuia W, Salles A, Gibson M, et al. Physician wellness in surgical residency. Curr Surg Rep 2018;6:1-16.

37 Low ZX, Yeo KA, Sharma VK, et al. Prevalence of burnout in medical and surgical residents: a meta-analysis. Int J Environ Res Public Health 2019;16:1479.

38 Maslach C, Jackson SE, Leiter MP. Maslach burnout inventory: consulting psychologists press Palo Alto, CA, 1986.

39 Tiffin PA, Orr J, Paton LW, et al. Uk nationals who received their medical degrees abroad: selection into, and subsequent performance in postgraduate training: a national data linkage study. BMJ Open 2018;8:e023060. 